\title{
MASCULINIDADES NO CONTEXTO ESCOLAR: COMO A TEMÁTICA É ABORDADA EM ARTIGOS PUBLICADOS EM DOSSIÊS DE PERIÓDICOS NACIONAIS
}

\section{HOMBRES EN EL CONTEXTO ESCOLAR: CÓMO SE ENFOQUE EL TEMA EN ARTÍCULOS PUBLICADOS EN DOSSIERS DE LA REVISTA NACIONAL}

MALE IN THE SCHOOL CONTEXT: HOW THE THEME IS APPROACHED IN ARTICLES PUBLISHED IN NATIONAL JOURNAL DOSSIERS

\author{
Luciana Aparecida Siqueira Silval \\ Elenita Pinheiro de Queiroz Silva ${ }^{2}$
}

\section{RESUMO}

Esse estudo emerge no contexto da produção de uma tese de doutorado em Educação, tendo como objetivo mapear artigos publicados em periódicos nacionais, que compõem dossiês sobre corpo, gênero e sexualidade, e, a partir deles apresentar a produção de estudos sobre masculinidades no contexto escolar. A construção das subjetividades é atravessada por modelos de ser homem e de ser mulher, relacionando-se a padrões estabelecidos socioculturalmente, inclusive na escola. No mapeamento, foram identificados 11 artigos produzidos entre 1998 e 2018, apontando que, nas interações vividas nas escolas, distintos discursos de masculinidades e sexualidades se entrelaçam e se atravessam, predominando o da masculinidade hegemônica e o da heterossexualidade compulsória. A escola possui importante papel a cumprir no sentido de desnaturalizar modelos hegemônicos de masculinidade, questionando expectativas em torno do que é dado como tipicamente feminino ou masculino, sendo urgente que outras educações sobre as masculinidades sejam desenhadas e praticadas nos contextos escolares.

PALAVRAS-CHAVE: Masculinidade. Contexto Escolar. Dossiês.

\section{RESUMEN}

Este estudio surge en el contexto de la producción de una tesis doctoral en Educación, con el objetivo de mapear artículos publicados en revistas nacionales, que componen dossieres sobre cuerpo, género y sexualidad, y de ellos presentar la producción de

${ }^{1}$ Mestra Biologia. Instituto Federal Goiano-Campus Urutaí, Goías.

${ }^{2}$ Doutora em Educação pela Universidade Federal de Uberlândia. 
Masculinidades no contexto escolar: como a temática é abordada em artigos publicados em dossiês de periódicos nacionais

estudios sobre masculinidades en el contexto escolar. La construcción de subjetividades está atravesada por modelos de ser hombre y de mujer, en relación con los estándares establecidos socioculturalmente, incluso en la escuela. En el mapeo, se identificaron 11 artículos producidos entre 1998 y 2018, señalando que, en las interacciones vividas en las escuelas, los diferentes discursos de masculinidades y sexualidades se entrelazan e intersectan, predominantemente la masculinidad hegemónica y la heterosexualidad obligatoria. La escuela tiene un papel importante que desempeñar en el sentido de desnaturalizar los modelos hegemónicos de masculinidad, cuestionando las expectativas en torno a lo que se considera típicamente femenino o masculino, y es urgente que otras educaciones sobre masculinidades se diseñen y practiquen en contextos escolares.

PALABRAS-CLAVE: Masculinidad. Contexto Escolar. Dossiers.

\section{ABSTRACT}

This study emerges in the context of the production of a doctoral thesis in Education, with the objective of mapping articles published in national journals, which make up dossiers on body, gender and sexuality, and from them present the production of studies on masculinities in the school context. The construction of subjectivities is crossed by models of being a man and of being a woman, relating to standards established socioculturally, including at school. In the mapping, 11 articles produced between 1998 and 2018 were identified, pointing out that, in the interactions lived in schools, different discourses of masculinities and sexualities intertwine and intersect, predominantly hegemonic masculinity and compulsory heterosexuality. The school has an important role to play in the sense of denaturalizing hegemonic models of masculinity, questioning expectations around what is considered to be typically feminine or masculine, and it is urgent that other educations on masculinities be designed and practiced in school contexts.

KEYWORDS: Masculinity. School Context. Dossiers.

$$
* * *
$$

No dia em que fotografias com homens carregando armas se tornarem raras e fotografias com homens empurrando carrinhos de bebê se tornarem comuns, aí saberemos que estamos realmente chegando a algum lugar. Raewyn Connell (1995, p. 205)

\section{Introdução}

O presente estudo emerge no contexto de produção de uma tese de doutorado em Educação $^{3}$, vinculada ao Programa de Pós-graduação em Educação da Universidade Federal de Uberlândia (PPGED/UFU), da Linha de pesquisa Educação em Ciências e Matemática, onde se insere o Grupo de Pesquisa Gênero, Sexualidade e Educação

${ }^{3}$ A pesquisa é parte do Projeto de Pesquisa "Saberes sobre corpo, gênero e sexualidades em manuais escolares/livros didáticos de biologia - Brasil/Portugal". Chamada universal 01/2016 - CNPQ/MCTI, coordenado pela Profa. Dra. Elenita Pinheiro de Queiroz Silva, Universidade Federal de Uberlândia/UFU, Brasil. 
(GPECS). Tal grupo de pesquisa tem como uma das propostas de atividades o levantamento de investigações realizadas e em curso, apresentadas em base de dados onde são publicados artigos acadêmicos, frutos de pesquisas, conforme o trabalho desenvolvido por Santos e Silva (2017). Nessa perspectiva, a busca por dossiês torna-se relevante, por considerarmos que os periódicos que compõem estas bases constituem-se em espaços de divulgação científica que passam, no Brasil, pelos seguintes processos de avaliação: os desencadeados por agências como a Coordenação de Aperfeiçoamento de Pessoal de Ensino Superior (CAPES); e os relativos à publicação no âmbito dos periódicos, que instituem pareceristas ad hoc (pesquisadores(as) com pesquisa reconhecida no campo de conhecimento). Desse modo, temos o objetivo de apresentar o mapeamento de artigos publicados em periódicos nacionais, que compõem dossiês sobre corpo, gênero e sexualidade e, a partir deles, apresentar a produção de estudos, concluídos ou em andamento, sobre masculinidades no contexto escolar.

Estudo das masculinidades e seus entrelaçamentos com o conceito de gênero: considerações iniciais

No Brasil, o estudo das masculinidades ${ }^{4}$ começou a ser desenvolvido sistematicamente a partir da década de 1990. Benedito Medrado e Jorge Lyra (2018) salientam que, antes disso, "praticamente toda a literatura brasileira que se referia a gênero tratava quase exclusivamente sobre as mulheres e a condição feminina" (p. 7). Esses estudos iniciais estiveram centrados no argumento de que os homens estariam vivenciando uma crise fundamentada em diversas causas, dentre as quais se destacariam os questionamentos feministas contra a "posição dominadora e patriarcal dos homens na sociedade e na família" (LISBOA, 1998, p. 131) e "a ascendência da discussão acerca das mudanças nos papéis masculinos e femininos na sociedade contemporânea" (MACHADO, 2016, p. 52). De acordo com os autores referidos, torna-se inegável que o movimento feminista, permeado por lutas e reinvindicações pela igualdade de direitos das mulheres, provocou, ao longo dos anos, fissuras relativas às concepções de masculinidade, conceito que passa a ser (re)inventado em consonância com as conquistas

\footnotetext{
${ }^{4}$ Adotaremos o termo no plural: "masculinidades", por considerarmos, conforme Connell (1995), que não existe uma forma única de masculinidade, mas que "a masculinidade é uma configuração de prática em torno da posição dos homens na estrutura das relações de gênero (...). Falar de posição dos homens significa enfatizar que a masculinidade tem a ver com relações sociais e também se refere a corpos - uma vez que homens significa pessoas adultas com corpos masculinos (CONNELL, 1995, p. 187).
}

Revista Diversidade e Educação, v.7 , n.2 , p. 20-44 , Jul/Dez 2019. Doi: 10.14295/de.v7i2.963

E-ISSN: $2358-8853$ 
Masculinidades no contexto escolar: como a temática é abordada em artigos publicados em dossiês de periódicos nacionais

femininas. Assim, a partir da segunda metade do século XX, foram desencadeados acalorados debates que questionam concepções sobre a masculinidade e sobre o homem até então naturalizadas, provocando mudanças de olhares relativos às relações sociais, sexuais e raciais, especialmente no que diz respeito ao modelo dominante de masculinidade (branco, cisgênero ${ }^{5}$ e heterossexual). Desse modo, torna-se, a nosso ver, imprescindível a compreensão da historicidade das relações de gênero, para que seja possível perceber as interlocuções relativas ao masculino e ao feminino, uma vez que "a transformação dos modelos vigentes de masculinidades bebeu na fonte de movimentos sociais importantes, como o feminista, o movimento de mulheres, negro, LGBT, entre outros" (NASCIMENTO, 2018, p. 25).

Quando mergulhamos nas leituras desses campos, constatamos que, inicialmente, destacou-se entre os estudos das masculinidades, a centralização de análises sob a perspectiva da sexualidade masculina, não sendo priorizadas temáticas tais como a da violência ou da paternidade, restritas a poucos estudos investigativos (LEAL; BOFF, 1996). Entretanto, nos últimos anos do século XX e começo do século XXI, os estudos relativos às masculinidades e seus entrelaçamentos com campos de sua produção têm sido crescentes, tomando a cultura, a política e a produção de subjetividades, para se pensar seus efeitos sociais, culturais e educativos. Sendo assim, as referidas transformações são fruto da ação política do movimento social e acadêmico, a partir da qual foi possível a emergência de importantes discussões na literatura acerca da identidade masculina e do 'novo homem', conceito assentado nas discussões de Reawyn Connell (1995) e Sócrates Nolasco (1993).

O denominado "novo homem, diz respeito à admissão de um homem "[...] que chora, que é fragilizado e assustado e necessita dividir o peso das grandes responsabilidades que lhes são cultural e socialmente impostas" (SOUZA, 2009, p. 134). Ele ganha espaço não só no meio acadêmico, como também passa a fazer parte do discurso da grande mídia, que movimenta e difunde modos de ser e imagens que confluem para a produção e sustentação de um imaginário social contraposto à normas ${ }^{6}$ previamente estabelecidas para a educação de meninos e de homens e que passam pelas

\footnotetext{
5 Jesus (2012) distingue pessoas cisgênero de transgênero a partir da concordância (no caso cis) ou da discordância (no caso trans) existente entre a identidade de gênero autodeclarada e o sexo anatômico designado no nascimento.

${ }^{6}$ Michel Foucault, em Vigiar e Punir (FOUCAULT, 1987-b), localiza historicamente como o poder opera por meio da disciplina em diversas instituições, como a prisão e a escola. Para o pensador, ao enquadrar-se na norma, estabelecida socialmente, o indivíduo moderno é produzido.
} 
Masculinidades no contexto escolar: como a temática é abordada em artigos publicados em dossiês de periódicos nacionais

diversas instâncias de produção do masculino. Assim, não se fala mais em uma única maneira de ser masculino, mas sim de masculinidades em torno das quais circulam uma diversidade de discursos ${ }^{7}$. Para Connell ${ }^{8}$, "a masculinidade é uma configuração de prática em torno da posição dos homens nas estruturadas relações de gênero" (CONELL, 1995, p. 188).

No movimento de mobilização e aproximação do campo dos estudos de masculinidades e, mesmo da construção social, histórica, política e acadêmica da ideia de masculinidade e, por conseguinte, de homem emergente nas últimas décadas, trazemos para este artigo algumas pistas sobre a produção do conceito de gênero. Para tanto, consideramos as diferentes disputas e negociações em torno do conceito gênero e da luta feminista, além de apresentamos breve demarcação de tal conceito, no campo dos estudos feministas.

Nesse movimento, lançamos mão do texto de Linda Nicholson (2000), teórica que evidencia que o conceito de gênero foi inicialmente desenvolvido e usado como oposição ao sexo. Ela situa tal evidência a partir da maneira que as feministas da década de 1960 definem o gênero: como a representação social da conformação biológica daquilo que seria naturalmente dado. Entre as décadas de 1960 e 1990, o conceito gênero é reelaborado e, a partir desta última década, passa a ser tomado com um sentido inteiramente diverso da lógica do determinismo biológico sobre as categorias homem e/ou mulher.

A partir dos anos 90 do século XX, gênero aparece ligado às construções sociais, aos significados e símbolos atribuídos ao sexo biológico, ao longo da história. Ou seja, o gênero passa a ser pensado como referência aos papéis e aos comportamentos sociais e culturais; enquanto o sexo fica atrelado às características biológicas, com centralidade na Anatomia e Fisiologia humanas, sobretudo em uma anatomo-fisiologia que aponta para a demarcação do que é um corpo de homem e de mulher, tendo como referência central os órgãos genitais. Nicholson (2000) defende que “o 'sexo' permanece na teoria feminista como aquilo que fica de fora da cultura e da história, sempre a enquadrar a diferença feminino/masculino" (p. 10).

\footnotetext{
${ }^{7} \mathrm{Na}$ esteira do pensamento foucaultiano, o "discurso constitui-se de um conjunto de enunciados que se apoiam na mesma formação discursiva” (FOUCAULT, 1987, p. 135). É materializado pela linguagem e emerge a partir de condições de possibilidades em um determinado contexto histórico. Desse modo, "o discurso não é simplesmente aquilo que traduz as lutas ou os sistemas de dominação, mas aquilo por que, pelo que se luta, o poder do qual nos queremos apoderar" (FOUCAULT, 1996, p. 10).

${ }^{8}$ Raewyn Connell é uma cientista social australiana transexual de renome internacional, que iniciou seu percurso acadêmico como Robert Connell.
} 
Masculinidades no contexto escolar: como a temática é abordada em artigos publicados em dossiês de periódicos nacionais

Em $1975^{9}$, Gayle Rubin propõe-se a alcançar uma definição mais completamente desenvolvida sobre o conceito gênero, elaborando um ensaio intitulado " $O$ tráfico de mulheres: notas sobre a economia política do sexo", no qual lança a expressão 'sistema sexo-gênero'. Tal sistema diz respeito a "um conjunto de arranjos através dos quais a sociedade transforma a sexualidade biológica em produtos da atividade humana, e nos quais essas necessidades sexuais transformadas são satisfeitas" (RUBIN, 1993, p. 2). Conforme tal concepção, os aspectos biológicos são considerados como a base para a construção dos significados culturais, ou seja, "ainda veem a fisiologia humana como um 'dado' no qual as características específicas são 'sobrepostas', um 'dado' que fornece o lugar a partir do qual se estabelece o direcionamento das influências sociais" (NICHOLSON, 2000, p. 11).

Dessa forma, os estudos das masculinidades se desenvolveram atrelados às discussões relativas aos conceitos de sexo e gênero. Em "O mito da Masculinidade", Nolasco (1993) sugere que, ao criticar as relações de poder e hierarquia existentes entre homens e mulheres, o movimento feminista conduz uma nova reflexão teórica: a utilização do gênero como categoria analítica (SCOTT, 1990), inserindo o tema masculinidade na agenda científica.

No decorrer da obra "Gênero: uma categoria útil de análise", Joan Scott, apresenta como a terminologia gênero é empregada e consolidada a partir das relações de poder, além de tecer críticas às formas descritivas de análise para o termo. A historiadora evidencia que não é possível pensar em uma definição consensual relativa ao conceito de gênero; esta é uma tarefa laboriosa ao seu olhar, tendo sido a alternativa por ela sugerida considerar gênero como categoria de análise histórica. Propõe assim a ideia de que ser homem ou mulher não é algo que possa ser determinado pela biologia, mas construído socialmente a partir da atribuição de papéis sociais que vão sendo construídos. Scott (1990) e várias feministas a ela aliadas, passa a considerar que a concepção de gênero como uma categoria de análise nos auxilia a desvendar relações de poder, o que permite a compreensão mais ampla acerca das representações sociais configuradas para as identidades de gênero e como os sujeitos constituem no cotidiano essas representações. Para a teórica, o conceito de gênero

${ }^{9}$ O artigo foi traduzido para a Língua Portuguesa em 1993 por Christine Rufino Debat, Edileusa Oliveira da Rocha e Sônia Corrêa, optando-se aqui pela citação literal da obra traduzida. 
Masculinidades no contexto escolar: como a temática é abordada em artigos publicados em dossiês de periódicos nacionais

tem duas partes e várias sub-partes. Elas são ligadas entre si, mas deveriam ser analiticamente distintas. O núcleo essencial da definição baseia-se na conexão integral entre duas proposições: o gênero é um elemento constitutivo de relações sociais baseado nas diferenças percebidas entre os sexos, e o gênero é uma forma primeira de significar as relações de poder (SCOTT 1990, p. 21).

Scott (1990) considera o gênero como parte constitutiva das relações sociais para além das diferenças que são percebidas entre os sexos, afirmando que

nós só podemos escrever a história desse processo se reconhecermos que 'homem' e 'mulher' são, ao mesmo tempo, categorias vazias e transbordantes. Vazias, porque não têm nenhum significado último, transcendente. Transbordantes, porque mesmo quanto parecem estar fixadas, ainda contêm dentro delas definições alternativas, negadas ou suprimidas (SCOTT, 1990, p. 93).

De acordo com a proposição de Scott (1990), o sujeito não pode ser pensado como, exclusivamente, um produto social e nem como, essencialmente, biológico. Essa divisão entre construto social e biológico deve ser relativizada, no sentido de que ambos estão contidos um no outro. Em outro texto, Joan W. Scott afirma: "a emergência da história das mulheres como um campo de estudo envolve, nesta interpretação, uma evolução do feminismo para as mulheres e daí para o gênero; ou seja, da política para a história especializada e daí para a análise” (SCOTT, 1992). A formulação de Scott (1990) ganhou muitas adesões, mas também sofreu inúmeras críticas, tanto dentro quanto fora do campo dos estudos feministas.

Ao recorrermos a pesquisadoras do campo dos estudos feministas no Brasil, encontramos Heloísa Buarque de Hollanda (1994) que organiza um importante livro intitulado "Tendências e impasses: o feminismo como crítica da cultura". Na introdução desta obra, Hollanda pontua que a crítica feminista debate as determinações históricas e políticas sobre mulheres e homens, além de assinalar que a questão da significação passa a ocupar as agendas teóricas feministas aliadas à pós-modernidade.

$\mathrm{Na}$ esteira dos estudos de gênero, não nos é possível deixar de falar sobre a crítica feminista tecida por Judith Butler. Tal crítica, traduzida em sua célebre obra "Gender Trouble: Feminism and the Subversion of Identity" $(1990)^{10}$, é fundamental para a teoria feminista e todas as discussões contemporâneas que se desdobram sobre o conceito gênero. Para discutir tal conceito, Butler traça um percurso que parte da crítica feminista

${ }^{10}$ A obra teve sua primeira tradução para o português no ano de 2003, publicada pela Editora Civilização Brasileira, sob o título "Problemas de Gênero". 
Masculinidades no contexto escolar: como a temática é abordada em artigos publicados em dossiês de periódicos nacionais

para discutir a construção das identidades dos sujeitos. Ao tecer críticas ao feminismo ela não se afasta de suas bases fundantes, mas busca ampliar os limites do que já havia sido pensado e proposto pelo feminismo, pois considera que só é possível a construção de sujeitos sociais a partir de uma construção de gênero. A filósofa realizou o exercício teórico de demonstrar como funciona a construção do gênero feminino para assim poder demonstrar as contradições existentes no conceito, buscando afastar-se dos binarismos de gênero.

As teorizações anteriormente propostas por Gayle Rubin são importantes para a autora, no entanto, o que Butler percebe é que a distinção sexo/gênero considerada até então não estaria fundada em bases tão firmes quanto o pressuposto anterior a ela. Em suas palavras,

concebida originalmente para questionar a formulação de que a biologia é o destino, a distinção entre sexo e gênero atende à tese de que, por mais que o sexo pareça intratável em termos biológicos, o gênero é culturalmente construído: consequentemente, não é nem o resultado causal do sexo nem tampouco tão aparentemente fixo quanto o sexo (BUTLER, 2003, p.26).

Observamos que, tanto a filósofa, Judith Butler, quanto a historiadora, Joan Scott, empreendem um exercício analítico no sentido de demonstrarem que as categorias sexo e gênero estão intimamente envolvidas e mobilizam formas de saber, conhecimentos no entorno das noções de corpo, diferenças sexuais e, também, do que é produzido socialmente como sujeitos sexuados. Para Scott, gênero e sexo são conceitos históricos, portanto, sofrem variações no tempo e no espaço; o gênero produz efeitos sobre o sexo. Para Butler (2003, p. 27), o sexo sempre foi gênero, desde o começo e "o sexo não poderia qualificar-se como uma facticidade anatômica pré-discursiva".

Butler, considera o gênero como intricado em relações de poder e pensa o poder a partir das obras de Michel Foucault. Em seu movimento teórico, a filósofa problematiza a heterossexualidade como uma identidade compulsória, sobre a qual operam o poder e o discurso. A autora afirma que "a categoria das mulheres só alcança estabilidade e coerência no contexto da matriz heterossexual” (BUTLER, 2003, p. 23). O gênero produz efeitos sobre o corpo sexuado, e o binarismo sexual não determina o gênero.

Se o gênero são os significados culturais assumidos pelo corpo sexuado, não se pode dizer que ele decorra, de um sexo desta ou daquela 
maneira. Levada a seu limite lógico, a distinção sexo/gênero sugere uma descontinuidade radical entre corpos sexuados e gêneros culturalmente construídos. Supondo por um momento a estabilidade do sexo binário, não decorre daí que a construção de "homens" se aplique exclusivamente a corpos masculinos, ou que o termo "mulheres" interprete somente corpos femininos. Além disso, mesmo que os sexos pareçam não problematicamente binários em sua morfologia e constituição (ao que será questionado), não há razão para supor que os gêneros também devam permanecer em número dois (BUTLER, 2003, p. 24).

Desse modo, parte dos estudos das masculinidades na contemporaneidade, estabelecem diálogos com os estudos de Butler. Dialogam ainda com teorizações decoloniais que interpretam sexo e gênero como imposições coloniais constituídas por complexas teias de relações que se materializam na produção/regulação de subjetividades masculinas. Este é um campo de estudos que, embora recente, se considerados os estudos sobre mulheres, já nos apresenta uma gama de perspectivas e análises. Assim, se tomarmos o campo escolar, veremos o quanto a marca da complexidade é importante para fazer pensar o entrelaçamento masculinidades e educação escolarizada. Essa é a proposta que apresentamos no tópico que segue.

\section{Masculinidades no território escolar: campo de tensões e (des)construções}

Ao voltarmos o olhar para a escola, não é difícil identificarmos que este constituise como um território de disputas, que passam pelas tensões relativas às relações de gênero e de poder. A escola participa da construção das subjetividades desde a mais tenra idade, e ela o faz, na maioria das vezes, defendendo modelos hegemônicos de ser homem e de ser mulher. Tais modelos se relacionam a padrões estabelecidos pela cultura e por conjuntos de crenças vigentes em cada sociedade, em cada tempo histórico. Conforme Connell (1995), masculinidades e feminilidades não estão dadas por uma biologia que já estaria dada. Elas são construções social, histórica, cultural, portanto, produtoras de subjetividades. Nesta linha de argumentação torna-se fundamental, a fim de que se tenha em conta o que pode a escola em uma dada sociedade, pensar tal instituição como um espaço/lugar que (re)produz (des)igualdades de gênero e de sexualidade. A escola tanto pode corroborar para a construção de realidades nas quais indivíduos se enquadram em padrões e normas ditas como únicas e universais (a heteronorma, o binarismo de gênero, portanto, modelo universal de feminilidade e de masculinidade), quanto pode 
Masculinidades no contexto escolar: como a temática é abordada em artigos publicados em dossiês de periódicos nacionais

problematizar e fazer circular as múltiplas constituições e expressões de feminilidades e masculinidades.

Ao estudarmos a história da sexualidade a partir de Michel Foucault, percebemos a escola como uma das instituições sociais em que o discurso relativo aos corpos e à sexualidade se organizou e foi disseminado. Contrariando diversas expectativas, a instituição pedagógica não silenciou a sexualidade, "ela concentrou as formas do discurso neste tema; estabeleceu pontos de implantação diferentes; codificou os conteúdos e qualificou os locutores" (FOUCAULT, 2007, p. 36). Nessa perspectiva, consideramos a escola como um espaço plural de construção de saberes, onde estudos e discussões inerentes às diversas manifestações da sexualidade humana podem (e devem) ocupar lugar de destaque.

Connell (1995; 2013) chama atenção para os riscos que corremos ao considerarmos as relações de gênero como dicotômicas, menosprezando as particularidades e complexidades existentes em cada contexto. Destaca o fato de que diferentes masculinidades podem ser construídas dentro do mesmo contexto, sendo possível pensar que, dentro de uma mesma instituição escolar, por exemplo, podem ocorrer modos diversos de masculinidade, com a presença do modelo hegemônico, assim como aqueles considerados marginalizados ou mesmo resistentes. Como existe certa contradição da masculinidade, é possível encontrá-la presente em mulheres, assim como a feminilidade presente em homens. Por essa razão, afirma que

a masculinidade não é uma entidade fixa encarnada no corpo ou nos traços da personalidade dos indivíduos. As masculinidades são configurações de práticas que são realizadas na ação social e, dessa forma, podem se diferenciar de acordo com as relações de gênero em um cenário social particular (CONNEL, 1995, p. 250).

O conceito de masculinidade hegemônica, problematizado por Connell (1995), aponta para a multiplicidade das masculinidades, isto é, para a (co)existência de diferenciados padrões que serão caracterizados como masculinidades hegemônicas, de subordinação, de cumplicidade e marginalizadas (CONNELL, 1995). Trata-se de um conceito suscetível a críticas por parte de diversos teóricos, por não ter um caráter fixo e apresentar um posicionamento passível de contestação. Connell e Messerschmidt (2013) ampliaram as discussões relativas à temática, afirmando que 
padrões múltiplos de masculinidade têm sido identificados em muitos estudos, em uma variedade de países e em diferentes contextos institucionais e culturais. Também é resultado de pesquisa bastante difundido o fato de que certas masculinidades são socialmente mais centrais ou mais associadas com autoridade e poder social do que outras. $\mathrm{O}$ conceito de masculinidade hegemônica presume a subordinação de masculinidades não hegemônicas, e esse é um processo que agora tem sido documentado em muitos contextos, em nível internacional (CONNELL; MESSERSCHMIDT, 2013, p. 262).

Para os autores, as noções de masculinidade e feminilidade são invenções históricas que variam de acordo com os contextos sociais e culturais, podendo ser diversas também dentro de um mesmo grupo de pares, existindo, por exemplo, diferentes noções e formas de "fazer" masculinidade entre alunos. Para além da pluralidade, consideram fundamental reconhecer que diferentes práticas de masculinidade estabelecem relações hierárquicas entre si, em recorrentes disputas pela hegemonia nas relações de gênero, estabelecendo-se constantes relações de poder.

Sobre o tema do poder, Foucault (2017) indaga como ele nos constitui, como opera na produção de nossos desejos, percebendo-o como uma 'teia, uma rede', disseminado pela sociedade, inclusive pelas instituições escolares. Segundo suas ideias, não existem relações de poder sem resistência, que não vem de fora, não é exterior ao poder, mas faz parte do próprio jogo de sua existência. No entanto, defende que a resistência somente poderá gerar mudanças na sociedade se houverem novas formas de organização de relações e de ideologia do saber por parte das pessoas que resistem ao poder. Nesse contexto, não considera a ideia de que o poder seja um sistema de dominação que a tudo controla e que não deixa espaço para a liberdade, afirmando que "se há relações de poder em todo o campo social, é porque há liberdade por todo o lado" (FOUCAULT, 2004, p. 277).

Na contemporaneidade, diversos estudos (CASTRO, 2018; SILVA JUNIOR, 2017; SEFFNER; SILVA, 2014; DAMICO; MEYER, 2010), dos mais variados campos do conhecimento, têm descrito e analisado as assimetrias de gênero, problematizando tal questão sob diversos matizes teóricos e epistemológicos. No campo da Educação, destaca-se a menor representatividade feminina em cargos de gestão e a maior presença de mulheres atuantes na Educação Básica (NASCIMENTO, 2018; SULZ, 2016; SOUZA, 2009; CARVALHO, 1998). Enquanto campo de disputas e de construção de saberes, a escola pode (e deve) atuar como espaço de produção de diferenças e de promoção de rupturas com padrões sociais previamente estabelecidos. Para Castro (2018), 
Masculinidades no contexto escolar: como a temática é abordada em artigos publicados em dossiês de periódicos nacionais

A educação em uma sociedade verdadeiramente democrática, comprometida com a diminuição das desigualdades, possui a enorme tarefa não só de desestabilizar os paradigmas de identidades femininas subalternizadas ideologicamente pelo machismo, mas também os modelos de identidades masculinas tóxicas, frutos do mesmo machismo (CASTRO, 2018, p. 76).

Dessa forma, conhecer o que tem sido pesquisado no Brasil sobre a construção das masculinidades no contexto escolar, torna-se essencial para novas investigações relativas à temática em questão ou ainda para o aprofundamento dos estudos já desenvolvidos. Sem dúvida, a consolidação do campo na área da educação é de fundamental importância para pensarmos e problematizarmos as educações que se realizam no espaço escolar, e como favorecem a produção de modos de atuação, implicados com processos de descolonização do pensamento e do conhecimento.

\section{Masculinidades no contexto escolar: o que dizem artigos publicados em} dossiês?

Na delimitação dos caminhos da pesquisa, para chegarmos aos dossiês, fizemos uso da ferramenta de busca do Google, na realização de uma busca on-line, com a combinação das seguintes palavras-chave: "dossiê+gênero+sexualidade" e "dossiê+masculinidade+educação". Na busca inicial, identificamos 200 artigos, distribuídos em 24 dossiês nacionais, sem a utilização de filtros por data, a fim de que o levantamento fosse mais abrangente. Dessa forma, alcançamos a produção nacional sobre masculinidades, em dossiês, desde a primeira publicação, datada do ano de 1998.

Após a cuidadosa leitura dos títulos, resumos e palavras-chave dos artigos de todos os dossiês, selecionamos 11 artigos distribuídos em 10 dossiês produzidos entre os anos de 1998 a 2018, abrangendo um período de 20 anos de produção acadêmica nesse campo de estudos (quadro 1).

QUADRO 1: Dossiês nos quais foram identificados artigos sobre masculinidades no contexto educacional

\begin{tabular}{|c|c|c|c|c|}
\hline $\begin{array}{c}\text { Dossiês } \\
\text { analisados }\end{array}$ & Periódico & Ano & $\begin{array}{c}\text { Número de artigos } \\
\text { sobre masculinidades } \\
\text { no contexto escolar }\end{array}$ & $\begin{array}{c}\text { Qualis do } \\
\text { periódico } \\
\text { em } \\
\text { Educação }\end{array}$ \\
\hline
\end{tabular}

11 Considerando a pouca produção e que é um campo novo na área da educação, não consideramos o Qualis. Nos interessava encontrar a produção e não nos voltarmos à quantificação atribuída por agências de fomento, como a CAPES. 
Masculinidades no contexto escolar: como a temática é abordada em artigos publicados em dossiês de periódicos nacionais

\begin{tabular}{|c|c|c|c|c|}
\hline $\begin{array}{c}\text { Dossiê } \\
\text { Masculinidade }\end{array}$ & $\begin{array}{l}\text { Revista Estudos } \\
\text { Feministas }\end{array}$ & 1998 & 1 & A1 \\
\hline $\begin{array}{l}\text { A educação das } \\
\text { masculinidades }\end{array}$ & Cadernos Pagu & 2010 & 3 & $\mathrm{~A} 2$ \\
\hline $\begin{array}{c}\text { História, } \\
\text { Sexualidade e } \\
\text { Educação }\end{array}$ & $\begin{array}{l}\text { MÉTIS: história } \\
\& \text { cultura }\end{array}$ & 2014 & 1 & $\mathrm{~B} 2$ \\
\hline $\begin{array}{c}\text { Gênero e } \\
\text { diversidade } \\
\text { sexual na } \\
\text { educação }\end{array}$ & Reflexão e Ação & 2016 & 1 & B1 \\
\hline $\begin{array}{c}\text { Gêneros e } \\
\text { Sexualidades: } \\
\text { desafios e } \\
\text { potencialidade } \\
\text { para a Educação } \\
\text { em tempos de } \\
\text { conservadorismos }\end{array}$ & Revista Ártemis & 2016 & 1 & B5 \\
\hline $\begin{array}{c}\text { Educação, } \\
\text { Sexualidade e } \\
\text { Gênero }\end{array}$ & $\begin{array}{l}\text { Revista Café } \\
\text { com Sociologia }\end{array}$ & 2017 & 1 & B5 \\
\hline $\begin{array}{l}\text { Corpo, gênero e } \\
\text { sexualidade: } \\
\text { discursos, } \\
\text { sujeitos e práticas } \\
\text { educativas }\end{array}$ & Revista Margens & 2017 & 1 & $\mathrm{~B} 4$ \\
\hline $\begin{array}{l}\text { Dossiê Gênero e } \\
\text { Educação }\end{array}$ & Aprender & 2018 & 1 & $\mathrm{C}$ \\
\hline $\begin{array}{l}\text { Gênero, corpo e } \\
\text { identidades: } \\
\text { saberes e poderes } \\
\text { em debate }\end{array}$ & $\begin{array}{c}\text { Científic@ - } \\
\text { Multidisciplinary } \\
\text { Journal }\end{array}$ & 2018 & 1 & $\mathrm{C}$ \\
\hline \multicolumn{3}{|c|}{ TOTAL DE ARTIGOS } & 11 & \\
\hline
\end{tabular}

Fonte: Mapeamento realizado pelas pesquisadoras.

Com o exposto no quadro 1, encontramos no Cadernos Pagu o maior número de publicações sobre a temática: três artigos, no ano de 2010. Por seu turno, localizamos apenas dois dossiês que carregam no título o termo masculinidades: Dossiê Masculinidade (1998), publicado pela Revista Estudos Feministas e A educação das masculinidades (2010), publicado pelo Cadernos Pagu. Note-se que são dois periódicos especializados no campo dos estudos feministas e de gênero. 
Masculinidades no contexto escolar: como a temática é abordada em artigos publicados em dossiês de periódicos nacionais

A partir da organização e sistematização dos artigos encontrados, foi realizada a leitura integral dos textos dos artigos contendo abordagens de masculinidades, vinculados ao âmbito da educação escolar, não tendo sido considerados artigos que versassem sobre outros aspectos relativos à temática, uma vez que tivemos a intenção de estabelecer um recorte acerca da produção intelectual no país sobre masculinidades no contexto escolar. Diante disso, passamos a buscar respostas ao seguinte questionamento: o que têm indagado as/os pesquisadoras/es em Educação no que se refere às masculinidades e seu entrelaçamento com o contexto escolar? Assim, buscamos pelos objetivos das pesquisas e suas principais conclusões, que serão apresentadas a seguir.

\section{O que dizem os artigos analisados?}

A Revista Estudos Feministas publicou em 1998 o Dossiê Masculinidade, no qual Marilia Pinto de Carvalho contribuiu com o artigo "Vozes masculinas numa profissão feminina". O texto é produzido numa época em que o estudo sobre masculinidades era considerado como uma área emergente no campo da pesquisa dos estudos de gênero. A autora salienta que os próprios estudos de gênero eram escassos no campo educacional naquele período (final dos anos 90 do século XX, no Brasil), e, em sua pesquisa, da qual resultou o artigo, ela objetivou apreender as tensões e acomodações entre as identidades masculinas e o trabalho na escola, por meio da pesquisa com professores primários do sexo masculino de São Paulo. O artigo apresenta uma revisão de literatura, em língua inglesa, e entrevistas com professores primários, além de discutir os conceitos de masculinidade hegemônica e feminização da carreira docente. A pesquisadora conclui que existem formas de cuidado infantil que podem ser associadas à masculinidade, "diferentes daquelas das professoras, por envolverem mais claramente atividades físicas amplas, competitividade e autoridade, mas ainda assim, práticas de cuidado. E estão mostrando que existem, na personalidade de homens, elementos que o senso comum considera como femininos" (CARVALHO, 1998, p. 424).

O dossiê A educação das masculinidades, publicado em 2010, pelo periódico Cadernos Pagu apresenta três artigos que abordam o território escolar como tema de estudo. Conta com a contribuição de Amélia Cristina Abreu Artes e Marília Pinto de Carvalho, com o artigo "O trabalho como fator determinante da defasagem escolar dos meninos no Brasil: mito ou realidade?". As autoras buscam avaliar a influência do 
trabalho nas trajetórias escolares a partir dos microdados da Pesquisa Nacional de Amostra por Domicílio (PNAD 2006). Com base nesses dados, desenvolveram uma modelagem estatística, visando explicar a defasagem entre idade e anos de estudo considerando a variável sexo, além de considerarem o fator trabalho como variável de controle. O estudo apresenta como objetivo confrontar o discurso majoritário que explica os problemas de desempenho constatados entre os meninos como consequência de fatores externos à escola, em especial a inserção no mercado de trabalho. Concluem as autoras que "na escolarização brasileira, os meninos pobres e negros são o grupo que mais enfrenta dificuldades" (ARTES; CARVALHO, 2010, p. 70). As autoras buscam se afastar de uma análise binária que trate os grupos de mulheres e de homens como opostos e dicotômicos entre si e confirmam que no Brasil, "os meninos se encontram em uma situação de maiores dificuldades em sua trajetória escolar, medida por meio da defasagem entre idade e anos de estudo" (ARTES; CARVALHO, 2010, p. 71).

No artigo "Escolarización secundaria: asignaturas pendientes y expresiones en materia de inequidades de género", Ana Miranda e Analía Otero apresentam uma análise das principais atividades dos jovens em relação à participação no trabalho e às obrigações extra-escolares, propondo uma série de questões guiadas pelo questionamento de como tais atividades podem afetar a continuidade no ensino médio. Dedicando-se a contribuir para o debate sobre desigualdade social, analisam as tendências da evolução do acesso ao diploma do ensino médio entre homens e mulheres de diferentes grupos sociais da Argentina, bem como as principais atividades educacionais e trabalhistas dos jovens. No artigo, as autoras objetivaram discernir até que ponto a participação em atividades domésticas e trabalhistas pode afetar a continuidade educacional e o desempenho escolar. As autoras evidenciam que as mulheres são predominantemente responsáveis pelos trabalhos de casa, sendo uma característica da distribuição de ocupações por gênero. No entanto, notam a influência social, sendo que as pessoas com menor renda assumem esse tipo de responsabilidade com mais intensidade (MIRANDA; OTERO, 2010). Destacam ainda a disponibilidade diferencial dos alunos em relação ao tempo dedicado às atividades escolares, enfatizando a carga desigual de responsabilidades e obrigações domésticas e trabalhistas às quais os alunos do ensino médio de diferentes setores sociais estão expostos. Outro aspecto relevante foi a constatação de que estudantes de camadas econômicas de alta renda enfrentam obrigações trabalhistas e domésticas mais amenas em relação aos jovens dos setores sociais com menos poder econômico, que são impelidos a conciliar trabalho e estudos. 
Masculinidades no contexto escolar: como a temática é abordada em artigos publicados em dossiês de periódicos nacionais

Isabel de Oliveira e Silva e Iza Rodrigues da Luz (2010) analisam as concepções de educadoras sobre a educação de meninos no contexto institucional no artigo intitulado "Meninos na Educação Infantil: o olhar das educadoras sobre a diversidade de gênero". As estudiosas voltam seus olhares para uma imagem de masculinidades e para a questão do compartilhamento dos cuidados e da educação das crianças de 0 a 3 anos entre família e escola. Após analisarem a organização das experiências dos meninos, sob o ponto de vista das possibilidades de participação em diferentes situações e relações no ambiente escolar, concluem que "há uma dimensão de exclusão que envolve tanto práticas culturais como algumas possibilidades de trocas afetivas, marcadas por concepções do masculino presentes entre as educadoras" (SILVA; LUZ, 2010, p. 36), que priva os meninos de maior contato corporal e afetivo e de experiências significativas de convivência e brincadeiras tidas como adequadas somente para as meninas, reforçando $\mathrm{e}$ institucionalizando os estereótipos de gênero presentes nos mais diversos setores da sociedade.

O periódico MÉTIS: história \& cultura, por seu turno, publicou em 2014, o dossiê História, Sexualidade e Educação, que conta com a colaboração do texto produzido por Fernando Seffner e Luciano Ferreira da Silva: “Canetas coloridas ou mini-skates? coisas de meninas e coisas de meninos na cultura escolar". Ao longo do artigo, os autores enfocam as diferenças na construção de subjetividades de meninos e meninas como forma de gerar desigualdades ou vulnerabilidade social. Ressaltam que, na vida em sociedade, os homens dominam amplamente as melhores oportunidades profissionais e os melhores salários e, nesse sentido, problematizam as diferenças de gênero nos percursos escolares da escola pública brasileira. Ressaltam que no território escolar, "as melhores alunas são as meninas, com melhores notas e melhor desempenho. Mais meninas concluem o Ensino Médio, e mais meninas têm chegado às universidades" (SEFFENR; SILVA, 2014, p. 31). Esses paradoxos são discutidos, pelos autores, a partir de algumas cenas escolares, por meio das quais os autores "supõem a existência de conflitos entre os modos hegemônicos de construção da masculinidade e o ideal de bom aluno na escola" (SEFFENR; SILVA, 2014, p. 31).

A partir de 2016, observamos uma regularidade, embora pequena estatisticamente, de publicações em dossiês abordando as masculinidades em contextos escolares, ano em que o periódico Reflexão e Ação torna público o dossiê Gênero e diversidade sexual na educação. Nele, Márcio Rodrigo Vale Caetano, Paulo Melgaço da Silva Junior e Treyce 
Ellen Silva Goulart publicam o artigo "Masculinidades hegemônicas e dissidências: tensões curriculares em cotidianos de escolas da periferia". No estudo realizado, os autores e a autora do artigo propuseram reflexões sobre a importância de a escola estar atenta às questões de gênero e sexualidades, sobretudo questionando as práticas curriculares. A pesquisa busca questionar os modos como as masculinidades hegemônicas de duas escolas públicas da região da Baixada Fluminense do Rio de Janeiro são performatizadas e como elas interagem com as identidades sexuais dissidentes. Observam que "nas interações vividas nas escolas, distintas masculinidades se entrelaçam e se atravessam. Entretanto, o discurso predominante entre os rapazes é o da masculinidade hegemônica" (CAETANO; SILVA JUNIOR; GOULART, 2016, p. 222).

Apesar de não se referirem diretamente ao ambiente escolar no artigo "Educação e políticas de masculinidades: 15 anos das produções dos Estudos de Gênero (20002015)", Juliana Sulz e Frederico Cardoso mapearam a produção científica sobre a temática, em dossiê que compõe a Revista Ártemis em 2016, sob o título Gêneros e Sexualidades: desafios e potencialidade para a Educação em tempos de conservadorismos. Diante do tímido crescimento de trabalhos acadêmicos, relatam a/o autora/or que abordam as masculinidades, foi realizado um levantamento de produções acerca do tema na Plataforma online da Coordenação de Aperfeiçoamento de Pessoal de Nível Superior (CAPES), tendo sido identificado 80 trabalhos, que foram categorizados em 07 grupos distintos que, conforme a/o estudiosa/o, "não traduzem a real totalidade das produções acadêmicas acerca das políticas de masculinidades" (SULZ; CARDOSO, 2016, p. 64). As pesquisas identificadas versaram sobre os temas: saúde masculina; homens na literatura; homens-professores no magistério; paternidade; violência doméstica/violência de gênero; identidades sexuais/ sexualidades masculinas e sobre homens; consumo; comportamento e mercado. Por meio do estudo, constataram que Connell foi o referencial teórico recorrente nas pesquisas identificadas e que "a maior parte dos trabalhos se preocupa em investigar o comportamento dos homens assinalando as transformações desses comportamentos, de pensamentos e de vivência da masculinidade" (SULZ; CARDOSO, 2016, p. 66). Importa ressaltar que no universo de 80 trabalhos identificados pelo artigo, apenas 7 se debruçaram sobre temáticas relativas aos entrelaçamentos entre masculinidades e educação. Segundo os autores, "é evidente que a Educação tem muito para contribuir no debate que busca romper com antigos paradigmas acerca de uma masculinidade que, paulatinamente, vem se transformando e 
Masculinidades no contexto escolar: como a temática é abordada em artigos publicados em dossiês de periódicos nacionais

evoluindo" (SULZ; CARDOSO, 2016, p. 66). Concluem ainda que "é necessário avançar em pesquisas que se comprometam em abandonar noções superficiais de mulher e de homem como identidades únicas, sem historicidade e rodeadas de essencialismos" (SULZ; CARDOSO, 2016, p. 67).

$\mathrm{O}$ artigo "Se der mole... eu passo o rodo: quando as questões de gênero, sexualidades, masculinidades e raça invadem o cotidiano escolar", de autoria de Paulo Melgaço da Silva Junior, faz parte do dossiê Educação, Sexualidade e Gênero publicado pela Revista Café com Sociologia em 2017. A partir da frase que compõe o título do artigo, proferida por um aluno de 15 anos durante uma aula de Artes, o autor discute as noções que os estudantes, por ele investigado, apresentaram sobre gênero, sexualidades, masculinidades e raça, evidenciando a necessidade de se inserir tais discussões em sala de aula. Aponta o autor do texto como seu objetivo central "buscar caminhos para problematizar as noções de gênero, de sexualidades, de masculinidades e de raça, trazendo à tona a necessidade de reconhecermos outras possibilidades" (SILVA JUNIOR, 2017, p. 57). Ele destaca o evidente predomínio do discurso da colonialidade, da heteronormatividade compulsória e da masculinidade hegemônica. Contudo, afirma que "um exercício sistemático de problematização de discursos naturalizados pode ocasionar o desenvolvimento de novas concepções de gênero, de sexualidades e de masculinidades, principalmente entre os rapazes, que necessitam se engajar nas políticas de gênero (SILVA JUNIOR, 2017, p. 53).

Ainda em 2017, foi publicado o dossiê Corpo, gênero e sexualidade: discursos, sujeitos e práticas educativas pela Revista Margens. Jairo Barduni Filho, Anderson Ferrari e Eduardo Simonini Lopes contribuíram com o texto "Um jornal na fronteira: breves considerações sobre a produção de masculinidades no semanário estudantil ' $O$ Bonde"". O estudo desenvolveu-se no âmbito da Escola Superior de Agricultura e Veterinária (ESAV), "que tinha como um de seus principais objetivos fomentar em Minas Gerais um espaço de produção de tecnologia agrícola capaz de intervir nos modos de produção das comunidades rurais" (BARDUNI FILHO; FERRARI; LOPES, 2017, p. 14). Os autores salientam que a ESAV teve sua fundação e consolidação como um local de estudo hegemonicamente masculino, nutrindo em um ethos institucional de disciplina, responsabilidade e racionalidade científica, denominado de "espírito esaviano". Um dos veículos de divulgação desse espírito foi o jornal estudantil "O Bonde”, que de 1945 e 1963, deu voz aos estudantes daquele campus estudantil. O estudo se propôs a analisar

Revista Diversidade e Educação, v.7 , n.2 , p. 20-44 , Jul/Dez 2019.

Doi: $10.14295 /$ de.v7i2.963

E-ISSN: $2358-8853$ 
artigos publicados pelo jornal, tendo observado que "O Bonde" funcionava como recurso de policiamento de atitudes. Os pesquisadores concluem que o semanário "se transformava em campo de fronteira de diferentes regimes de subjetivação, principalmente no que se refere à produção de masculinidades entre os discentes" (BARDUNI FILHO; FERRARI; LOPES, 2017, p. 11).

Susana de Castro em seu artigo "O papel das escolas no combate às masculinidades tóxicas" publicado em 2018 no dossiê Gênero e Educação, Revista Aprender, reflete sobre os efeitos do machismo e das identidades fixas, assim como sobre a importância de se considerar a escola como o espaço de mudança para o questionamento das bases de sustentação da cultura machista. A pesquisadora relaciona masculinidade tóxica com a busca por poder, que atrai os jovens das favelas e periferias urbanas ao tráfico de drogas, afirmando que "os jovens não trabalhariam no tráfico de drogas se não estivessem tão apegados às identidades masculinas hegemônicas e se o sistema capitalista global e a divisão internacional do trabalho não os excluíssem do mercado de trabalho formal (CASTRO, 2018, p. 79). Diante da realidade apresentada, salienta que "a escola possui um papel enorme a cumprir, desnaturalizando a divisão sexual do trabalho e as expectativas em torno do que é tipicamente feminino ou tipicamente masculino" (CASTRO, 2018, p. 82).

O dossiê Gênero, corpo e identidades: saberes e poderes em debate, publicado em 2018 pelo periódico Científic@: Multidisciplinary Journal, conta com a contribuição de Gilson Xavier de Azevedo por meio do artigo "A presença masculina em cursos de Pedagogia". O autor discute a presença masculina em cursos de Pedagogia, com o objetivo de refletir sobre o debate de gênero nesse curso, bem como suas ausências e presenças no cotidiano educacional. A partir da constatação de que, em meados do século XXI, a maioria das pessoas que ingressam no referido curso são mulheres, mas ao voltar os olhares para a pós-graduação talvez essa prevalência se atenue, apresenta o seguinte questionamento: o que isso está nos dizendo e por que o curso de Pedagogia, na sua formação inicial, mantém o predomínio feminino e, quando olhamos para a pósgraduação, encontramos um quadro diferente? Azevedo (2018) sugere que a história do curso de Pedagogia se entrelaça à história das mulheres, suas conquistas e tensões sociais. Desse modo, "a profissão docente permite às mulheres o acesso a um espaço público anteriormente frequentado apenas por homens" (AZEVEDO, 2016, p. 16) e salienta a forte tendência presente entre o grupo investigado em associar esse curso de formação de professores a atividades femininas. 
Masculinidades no contexto escolar: como a temática é abordada em artigos publicados em dossiês de periódicos nacionais

\section{Considerações finais}

Um hiato de 12 anos separa o primeiro dossiê, que trouxe um estudo sobre masculinidades no contexto escolar, e o segundo, publicado apenas em 2010, seguido por um período de mais quatro anos sem discussões em dossiês sobre a referida temática. A partir de 2016, tais estudos passaram a ser realizados e publicados com maior regularidade por periódicos científicos qualificados, que aumentaram a frequência de publicações específicas sobre os estudos de gênero e sexualidade e seus entrelaçamentos com a Educação. Tais publicações dizem respeito a sinais de consolidação de um campo de estudos, particularmente vinculados a programas de pós-graduação nas diversas áreas das Ciências Humanas, tais como: História, Psicologia, Educação, Antropologia. As investigações presentes nos artigos de cada dossiê são baseadas na ideia de que "uma nova política do gênero para os homens significa novos estilos de pensamento, incluindo uma disposição a não ter certezas e uma abertura para novas experiências e novas formas de efetivá-la" (CONNELL, 1995, p. 205).

No conjunto, os artigos publicados nos dossiês que levantamos, assinalam para o fato de que não se deve desconsiderar, nos estudos de masculinidades, os conceitos raça, gênero e classe, pois eles estão intimamente imbricados e interdependentes dos modos de pensar o masculino e seu modo de funcionamento. Os artigos apontam para a forte tendência em não se considerar masculino e feminino como categorias opostas, em consonância com um/a dos/as autores/as de maior influência no campo: Connell (1995; 2013 e outros).

Tanto a tarefa e representação do professor na educação infantil quanto a problematização da relação entre escola e trabalho, foram alvos dos etudos que pensaram a articulação entre masculinidade e educação escolar. É notória a afirmação das múltiplas e distintas masculinidades vividas e experienciadas em espaços como os do trabalho e da escola. As formas de viver e experimentar estes espaços, se considerada a classe social e econômica da qual participam os homens, fazem emergir modos singulares de exercício da masculinidade, não sendo possível pensar a masculinidade apartada da classe. De modo igual, a masculinidade sofre efeitos e é constituída também pelo atravessamento étnico-racial. A escolarização de meninos os priva de maior contato corporal e afetivo, de experiências, convivências e brincadeiras e termina por reforçar e institucionalizar modos 
Masculinidades no contexto escolar: como a temática é abordada em artigos publicados em dossiês de periódicos nacionais

de ser homem e de masculinidades. Desse modo, muitos são os paradoxos experimentados e vividos socialmente. Eles dizem respeito às diferentes e não equânimes experiências e oportunidades na vida de meninas e de meninos, que vão desde as profissionais e trabalhistas até aos cargos e salários que vão ocupar nos espaços do trabalho. De um lado, homens e mulheres heterossexuais e binários/as, do ponto de vista do gênero, têm oportunidades e salários diferenciados. Assim, os estudos apontam que nas interações vividas nas escolas, distintas masculinidades se entrelaçam e se atravessam. Entretanto, o discurso predominante entre os rapazes é o da masculinidade hegemônica e da heterossexualidade compulsória. A escola possui importante papel a cumprir no sentido de desnaturalizar os modelos hegemônicos de masculinidade, questionando as expectativas em torno do que é dado como tipicamente feminino ou masculino. Todos os estudos sinalizam para a necessidade de se avançar nas pesquisas que se comprometam com o abandono das noções uníssonas sobre as identidades mulher e homem. Tal tarefa exige compromissos com processos democráticos e de exercício das liberdades em todas as instâncias da vida.

Por fim, somos levadas a pensar em questões relativas às masculinidades no território escolar que ainda não foram ditas, ou que não tenham sido estudadas sistematicamente. Há, portanto, pistas a serem seguidas com os artigos analisados, sendo uma delas a de que é urgente que outras educações sobre as masculinidades sejam desenhadas e praticadas nos contextos escolares. Problematizar e pensar os contornos desses desenhos é uma das tarefas a ser realizada na continuidade dos estudos. Como afirmado por Santos e Silva (2017), consideramos que os artigos que levantamos permitem a "[...] aposta em outros devires-educação que frature o sistema pontual normativo e hierarquizador do corpo, dos sexos e dos gêneros".

\section{Referências}

ARTES, Amélia Cristina Abreu; CARVALHO, Marília Pinto de. O trabalho como fator determinante da defasagem escolar dos meninos no Brasil: mito ou realidade? Cadernos Pagu, Campinas, v. 1, n. 34, p.41-74, 2010. Disponível em: http://www.scielo.br/scielo.php?script=sci_issuetoc\&pid=0104833320100001\&lng=pt\&nrm=iso. Acesso em: 22 out. 2019.

AZEVEDO, Gilson Xavier de. A presença masculina em cursos de Pedagogia. Científic@ - Multidisciplinary Journal, [s.1.], v. 5, n. 1, p.4-19, 26 fev. 2018. Cientifica Multidisciplinary Journal. http://dx.doi.org/10.29247/2358-260x.2018v5i1.p4-19. 
Masculinidades no contexto escolar: como a temática é abordada em artigos publicados em dossiês de periódicos nacionais

BARDUNI FILHO, Jairo; FERRARI, Anderson; LOPES, Eduardo Simonini. Um jornal na fronteira: breves considerações sobre a produção de masculinidades no semanário estudantil "O Bonde". Revista Margens Interdisciplinar, Abaetetuba, v. 11, n. 17, p.1727, 25 jan. 2018. Universidade Federal do Para.

http://dx.doi.org/10.18542/rmi.v11i17.5432. Disponível em:

https://periodicos.ufpa.br/index.php/revistamargens/article/view/5432. Acesso em: 22 out. 2019.

BUTLER, Judith. Problemas de Gênero: feminismo e subversão de identidade. Tradução de Renato Aguiar. Rio de Janeiro: Civilização Brasileira, 2003.

CAETANO, Marcio Rodrigo Vale; SILVA JUNIOR, Paulo Melgaço da; GOULART, Treyce Ellen Silva. Masculinidades hegemônicas e dissidências: tensões curriculares em cotidianos de escolas da periferia. Reflexão e Ação, Santa Cruz do Sul, v. 24, n. 1, p.214232, 28 abr. 2016. APESC - Associacao Pro-Ensino em Santa Cruz do Sul.

http://dx.doi.org/10.17058/rea.v24i1.6851. Disponível em:

https://online.unisc.br/seer/index.php/reflex/article/view/6851. Acesso em: 22 out. 2019.

CARVALHO, Marilia Pinto de. Vozes masculinas numa profissão feminina. Revista Estudos Feministas, Florianópolis, v. 6, n. 2, p.406-424, 1998. Disponível em:

https://periodicos.ufsc.br/index.php/ref/issue/view/308/showToc. Acesso em: 22 out. 2019.

CASTRO, Susana de. O papel das escolas no combate às masculinidades tóxicas. Aprender: Cad. de Filosofia e Psic. da Educação, Vitória da Conquista, v. 1, n. 20, p.7582, 21 dez. 2018. Disponível em:

http://periodicos2.uesb.br/index.php/aprender/issue/view/321. Acesso em: 22 out. 2019.

CONNELL, Robert W.; MESSERSCHMIDT, James W. Masculinidade hegemônica: repensando o conceito. Revista Estudos Feministas, Florianópolis, v. 21, n. 1, p.241-282, 2013.

CONNELL, Raewyn. Políticas da masculinidade. Educação e Realidade, v. 2, n. 20. p. 185-206, 1995.

DAMICO, José Geraldo Soares; MEYER, Dagmar E. Estermann. Constituição de masculinidades juvenis em contextos "difíceis": vivências de jovens de periferia na França. Cadernos Pagu, Campinas, v. 1, n. 34, p.143-178, 2010. Disponível em: http://www.scielo.br/pdf/cpa/n34/a07n34.pdf. Acesso em: 22 out. 2019.

FOUCAULT, M. História da sexualidade: a vontade de saber. Trad. Maria Thereza de ALBUQUERQUE, M. T. de; GUILHON ALBUQUERQUE, J. A. 6. ed. Rio de Janeiro/São Paulo: Paz e Terra, 2017.

A ética do cuidado de si como prática da liberdade. In: Ditos \& Escritos V-Ética, Sexualidade, Política. Rio de Janeiro: Forense Universitária, 2004. A ordem do discurso. São Paulo: Loyola, 1996. A arqueologia do saber. Rio de Janeiro: Forense-Universitária, 1987(a). 
Masculinidades no contexto escolar: como a temática é abordada em artigos publicados em dossiês de periódicos nacionais

1987(b).

Vigiar e Punir: história da violência nas prisões. Petrópolis: Editora Vozes,

HOLLANDA, Heloísa Buarque de. (org). Tendências e Impasses: o feminismo como crítica da cultura. Rio de Janeiro: Rocco, 1994.

JESUS, Jaqueline Gomes. Trans-formações: poder e gênero nos novos tempos. Anais do $18^{\circ}$ Congresso Brasileiro de Psicodrama. Brasília: Federação Brasileira de Psicodrama, 2012.

LEAL, Ondina Fachel; BOFF, Adriane de Mello. Insultos, queixas, sedução e sexualidade: fragmentos de identidade masculina em uma perspectiva relacional. In: PARKER, Richard; BARBOSA, Regina M. (orgs.). Sexualidades Brasileiras. Rio de Janeiro: Relume-Dumará/Abia/IMS/UERJ, 1996, p. 119-135.

LISBOA, Maria Regina Azevedo. Masculinidade: as críticas ao modelodominante e seus impasses. In: PEDRO, Joana Maria; GROSSI, Miriam Pillar. Masculino, feminino, plural: gênero na interdisciplinaridade. Florianópolis: Ed. Mulheres, 1998, p. 131-138.

MACHADO, Bruna Farias. Estudos de masculinidades: a crise masculina, a masculinidade hegemônica e a paternidade em Onde estão os ovos?, de Fabrício Carpinejar. Mosaico, Rio de Janeiro, v. 7, n. 11, p.49-63, 2016. Disponível em: $<$ http://bibliotecadigital.fgv.br/ojs/index.php/mosaico/article/view/64777>. Acesso em: 23 out. 2019.

MEDRADO, Benedito; LYRA, Jorge. Em tempos de masculinidades coloniais em relevo, um intento de prefácio. In: CAETANO, Marcio; SILVA JÚNIOR, Paulo Melgaço da (Org.). De guri a cabra-macho: masculinidades no Brasil. Rio de Janeiro: Lamparina, 2018. Prefácio. p. 7-9.

MIRANDA, Ana; OTERO, Analía. Escolarización secundaria:: asignaturas pendientes y expresiones en materia de inequidades de género. Cadernos Pagu, Campinas, v. 1, n. 34, p.75-106, 2010. Disponível em: http://www.scielo.br/pdf/cpa/n34/a05n34.pdf. Acesso em: 22 out. 2019.

NASCIMENTO, Marcos. Essa história de ser homem: reflexões afetivo-políticas sobre masculinidades. In: CAETANO, Marcio; SILVA JÚNIOR, Paulo Melgaço da (Org.). De guri a cabra-macho: masculinidades no Brasil. Rio de Janeiro: Lamparina, 2018. Cap. 1. p. 16-27.

NICHOLSON, Linda. Interpretando o gênero. Revista Estudos Feministas, Florianópolis, v. 8, n. 2, p. 9, 2000. Disponível em:

https://periodicos.ufsc.br/index.php/ref/article/view/11917. Acesso em: 24 out. 2019. doi:https://doi.org/10.1590/\%x.

NOLASCO, Sócrates. O mito da masculinidade. $2^{\text {a }}$ ed. Rio de Janeiro: Rocco, 1993

RUBIN, Gayle. O tráfico de mulheres: notas sobre a 'Economia Política' do sexo. Tradução de Christine Rufino Dabat. Recife: SOS Corpo, 1993. 
Masculinidades no contexto escolar: como a temática é abordada em artigos publicados em dossiês de periódicos nacionais

SANTOS, Sandro Prado; SILVA, Elenita Pinheiro de Queiroz. O Entrelaçamento entre Educação Escolar e Transexualidade em Dossiês de Periódicos Nacionais Brasileiros (1995-2017). InterMeio: revista do Programa de Pós-Graduação em Educação, Campo Grande, MS, v. 23, n. 46, p. 39-61, 2017.

SCOTT, Joan Wallach. Gênero: uma categoria útil de análise histórica. Educação e Realidade, Porto Alegre, n. 2, p. 5-22, 1990.

SCOTT, Joan Wallach. História das mulheres. In: BURKE, Peter. (org.) A escrita da história: novas perspectivas. São Paulo, Unesp, 1992, pp.64-65.

SEFFNER, Fernando; SILVA, Luciano Ferreira da. Canetas coloridas ou mini-skates? coisas de meninas e coisas de meninos na cultura escolar. Métis: história \& cultura, Caxias do Sul, v. 26, n. 13, p.31-60, 2014. Disponível em:

http://www.ucs.br/etc/revistas/index.php/metis/article/view/2796. Acesso em: 22 out. 2019.

SILVA JUNIOR, Paulo Melgaço da. "Se der mole... eu passo o rodo": quando as questões de gênero, sexualidades, masculinidades e raça invadem o cotidiano escolar. Café Com Sociologia, Maceió, v. 6, n. 1, p.53-70, 2017. Disponível em: https://revistacafecomsociologia.com/revista/index.php/revista/article/view/789. Acesso em: 22 out. 2019.

SILVA, Isabel de Oliveira e; LUZ, Iza Rodrigues da. Meninos na Educação Infantil: o olhar das educadoras sobre a diversidade de gênero. Cadernos Pagu, Campinas, v. 1, n. 34, p.17-39, 2010. Disponível em: http://www.scielo.br/pdf/cpa/n34/a03n34.pdf. Acesso em: 22 out. 2019.

SOUZA, Márcio Ferreira de. As análises de gênero e a formação do campo de estudos sobre a(s) masculinidade(s). Mediações: Revista de Ciências Sociais, [s.1.], v. 14, n. 2, p.123-144, 15 dez. 2009. Universidade Estadual de Londrina.

http://dx.doi.org/10.5433/2176-6665.2009v14n2p123.

SULZ, Juliana A.; CARDOSO, Frederico A. Educação e Políticas de Masculinidades: 15 Anos das Produções dos Estudos de Gênero (2000-2015). Revista Ártemis, [s.1.], v. 22, n. 1, p.63-72, 26 dez. 2016. Portal de Periodicos UFPB. http://dx.doi.org/10.15668/18078214/artemis.v22n1p63-72. 